\title{
Downregulation of microRNA-132 indicates progression in hepatocellular carcinoma
}

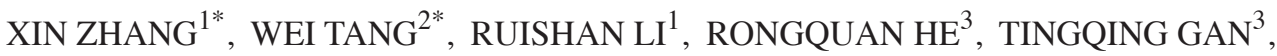 \\ YIHUAN LUO ${ }^{4}$, GANG $\mathrm{CHEN}^{4}$ and MINHUA RONG ${ }^{1}$ \\ ${ }^{1}$ Research Department; ${ }^{2}$ Department of Breast Surgery, Affiliated Cancer Hospital; Departments of ${ }^{3}$ Medical Oncology and \\ ${ }^{4}$ Pathology, First Affiliated Hospital, Guangxi Medical University, Nanning, Guangxi 530021, P.R. China
}

Received July 15, 2015; Accepted June 16, 2016

DOI: $10.3892 / \mathrm{etm} .2016 .3613$

\begin{abstract}
Although miR-132 has been studied in various human tumors, few studies have investigated the role of miR-132 in hepatocellular carcinoma (HCC). The present study aimed to evaluate the associations between miR-132 and clinicopathological parameters, including recurrence, in patients with HCC. Reverse transcription-quantitative polymerase chain reaction analysis was used to detect the expression levels of miR-132 in 95 cases of $\mathrm{HCC}$ and their corresponding non-cancerous liver tissues. Th e associations between miR-132 expression levels and clinicopathological characteristics, including recurrence, were investigated in patients with HCC. miR-132 expression levels were significantly reduced in HCC tissues, as compared with adjacent non-cancerous tissues (1.9245 \pm 0.7564 vs. 2.7326 $\pm 1.1475 ; \mathrm{P}<0.001)$. The area under curve (AUC) of receiver operating characteristic (ROC) used to distinguish cancerous and non-cancerous tissues was 0.711 for miR-132 expression (95\% confidence interval, 0.637-0.785; $\mathrm{P}<0.001$ ) and the optimal cut-off value was 2.25. Expression levels of miR-132 were significantly reduced in the distant metastasis $(\mathrm{P}=0.031)$, advanced clinical TNM stage $(\mathrm{P}=0.022)$, hepatitis $\mathrm{B}$ virus-positive $(\mathrm{P}<0.001), \mathrm{NM} 23$-expressed $(\mathrm{P}=0.034)$, high Ki-67 labeling index ( $\mathrm{LI} ; \mathrm{P}=0.005)$ and tumor infiltration or no capsule groups $(\mathrm{P}=0.026)$. Spearman correlation analysis demonstrated that miR-132 was significantly correlated with hepatitis $\mathrm{B}$ virus infection $(r=-0.351 ; \mathrm{P}<0.001), \mathrm{NM} 23$ $(r=-0.220 ; \mathrm{P}=0.032), \mathrm{Ki}-67 \mathrm{LI}(r=-0.264 ; \mathrm{P}=0.010)$ and tumor capsule $(r=-0.207 ; \mathrm{P}=0.044)$. Kaplan-Meier analysis with the log-rank test indicated an approximate difference of 8 months,
\end{abstract}

Correspondence to: Professor Minhua Rong, Research Department, Affiliated Cancer Hospital, Guangxi Medical University, 71 Hedi Road, Nanning, Guangxi 530021, P.R. China E-mail: tourtair@163.com

*Contributed equally

Key words: microRNA-132, hepatocellular carcinoma, reverse transcription-quantitative polymerase chain reaction, progression although miR-132 may exhibit inferior values for the prediction of recurrence in HCC patients (50.95 vs. 58.68 months; $\mathrm{P}=0.512$ ). Therefore, the findings of the present study indicated that miR-132 is downregulated in HCC and may serve as a tumor suppressor in its progression.

\section{Introduction}

Hepatocellular carcinoma (HCC) is the fifth most common cancer in men and the seventh in women worldwide, and it ranks third among the total number of deaths from cancer (1). HCC is particularly prevalent in Africa and eastern/south eastern Asia. Surgical resection and liver transplantation remains the optimal therapeutic strategy for the treatment of HCC. However, due to poor liver conditions, such as cirrhosis and liver dysfunction, only a minority of HCC patients are eligible for surgical intervention, and access to transplantation is limited by the scarcity of donor organs $(2,3)$. Furthermore, the majority of HCC patients are diagnosed during the late or end stages, thus missing the best opportunity for surgical resection. In addition, recurrence and metastasis are frequently detected in patients who undergo surgical resection and the postoperative 5-year survival rate remains low at 30-40\% (4). Therefore, it is of great importance that the potential initial molecular mechanisms of HCC progression are investigated in order to identify biomarkers that may be used to evaluate whether HCC patients are at high risk of metastasis or recurrence.

MicroRNAs (miRs) are a family of single-stranded, highly conserved, non-coding functional RNAs $(5,6)$. As $>50 \%$ of human miRs are located at fragile sites or in cancer-associated genomic regions (7), they may be used as novel biomarkers for the assessment of cancer and potential therapeutic targets. It has previously been reported that miRs act as tumor suppressive genes and oncogenes (8). Various studies have been performed to investigate the association between miRs and human tumors (9-11). Several metastasis-associated miRs have been detected in HCC, including miR-338, miR-19a and miR-122a (12). miR-132, which is located on human chromosome 17p13.3, has been associated with various human cancers including osteosarcoma, colorectal cancer $(13,14)$, breast cancer $(15,16)$, pancreatic cancer $(17-20)$, prostate cancer (21), gastric cancer $(22)$ and glioma $(23,24)$. 
Furthermore, Wei et al (25) also investigated the association between miR-132 and hepatitis B virus (HBV)-associated HCC. However, this study only included 20 paired samples and did not investigate the association between miR-132 and clinicopathological factors or recurrence in patients with HCC. To the best of our knowledge, there has been no investigation of the association between miR-132 levels and recurrence in any previous study to date. Therefore, a large cohort is required to validate the clinical significance of miR-132 in patients with HCC.

In the present study, reverse transcription-quantitative polymerase chain reaction ( $\mathrm{RT}-\mathrm{qPCR}$ ) was performed to assess the expression levels of miR-132 in HCC patients. Subsequently, the associations between miR-132 expression levels, clinical parameters and recurrence were investigated in patients with HCC.

\section{Materials and methods}

Patients and tissue samples. A total of 95 formalin-fixed, paraffin embedded (FFPE) HCC tissues and their matched adjacent non-cancerous liver tissues were obtained from patients who underwent surgery in the Department of Hepatobiliary Surgery at the First Affiliated Hospital of Guangxi Medical University (Nanning, China) between March 2010 and December 2011. The mean age of the enrolled patients was 52 years (range, 29-82 years), and the mean size of the tumors was $6.4 \mathrm{~cm}$ (range, $1-11 \mathrm{~cm}$ ). Pathologic diagnosis was independently performed by two experienced pathologists. A total of 75 men and 20 women were enrolled in the present study. The characteristics of the patients are shown in Table I. None of the patients had previously received preoperative treatments and the present hepatectomy was the first for each patient. The study protocol was approved by the Research Ethics Committee of the First Affiliated Hospital of Guangxi Medical University. Written informed consent was obtained from each patient.

RNA isolation and RT-qPCR. Total RNA was extracted from FFPE cancer $\left(\mathrm{OD}_{260 / 280}, 1.84-2.06\right)$ and adjacent non-cancerous liver tissues $\left(\mathrm{OD}_{260 / 230}, 1.90-2.04\right)$ using miRNeasy FFPE kit (73504; Qiagen AB, Sollentuna, Sweden), according to previous reports (26-29). Expression levels of miR-132 were evaluated using RT and qPCR kits. In order to remove genomic DNA, the following mixture with a total volume of $10.0 \mu \mathrm{l}$ was used: $2.0 \mu \mathrm{l} 5 \mathrm{X}$ gDNA Eraser buffer, $1.0 \mu \mathrm{l}$ gDNA Eraser, and trace amount of total RNA with extra RNase-free water. The mixture was maintained at $42^{\circ} \mathrm{C}$ for $2 \mathrm{~min}$ and then at $4^{\circ} \mathrm{C}$ until further use. Reverse transcription of total RNA into cDNA was performed with the TaqMan MicroRNA Reverse Transcription kit (4366596; Applied Biosystems; Thermo Fisher Scientific, Inc., Waltham, MA, USA) in a total volume of $20.0 \mu \mathrm{l}$, including $10.0 \mu \mathrm{l}$ from the previous step (removal of genomic DNA), $4.0 \mu 15 \mathrm{X}$ PrimeScript Buffer 2, $1.0 \mu$ l PrimeScript RTEnzyme Mix I, 1.0 $\mu \mathrm{l}$ RT Primer Mix, and 4.0 $\mu \mathrm{l}$ RNase-free water. qPCR analysis of miRNA was performed using a PCR7900 thermal cycler (Applied Biosystems; Thermo Fisher Scientific, Inc.). RNU6B and RNU48 were selected as endogenous controls. Primers were purchased from Applied Biosystems (Thermo
Fisher Scientific, Inc.) and the respective sequences were as follows: miR-132, UAACAGUCUACAGCCAUGGUCG; RNU6B, CGCAAGGAUGACACGCAAAUUCGUGAAGCG UUCCAUAUUUUU; and RNU48, GAUGACCCCAGGUAA CUCUGAGUGUGUCGCUGAUGCCAUCACCGCAGC

GCUCUGACC. NormFinder (MOMA, Aarhus, Denmark) and geNorm (genorm.cmgg.be) were used to select RNU6B and RNU48 as endogenous controls. PCR primers for miR-132, RNU6B and RNU48 were included in the TaqMan MicroRNA assay kit (4427975; Applied Biosystems; Thermo Fisher Scientific, Inc.). A PCR reaction system with a total volume of $20.0 \mu \mathrm{l}$ was employed, including $10.0 \mu \mathrm{l}$ LightCycler 480 SYBR Green I Master (Roche Diagnostics GmbH, Mannheim, Germany), $0.8 \mu \mathrm{l}$ PCR forward primer (10 $\mu \mathrm{M}), 0.8 \mu \mathrm{l}$ PCR reverse primer $(10 \mu \mathrm{M}), 1.0 \mu \mathrm{l}$ cDNA template $(<100 \mathrm{ng})$ and $7.4 \mu 1$ RNase-free water. A LightCycler 480 (Roche Diagnostics $\mathrm{GmbH}$ ) was used to perform PCR under the following conditions: Pre-denaturation at $95^{\circ} \mathrm{C}$ for $5 \mathrm{~min} ; 40$ cycles of $95^{\circ} \mathrm{C}$ for $10 \mathrm{sec}, 60^{\circ} \mathrm{C}$ for $10 \mathrm{sec}$, and $72^{\circ} \mathrm{C}$ for $10 \mathrm{sec}$; analysis of solubility curve at $95^{\circ} \mathrm{C}$ for $5 \mathrm{sec}$ and $65^{\circ} \mathrm{C}$ for $1 \mathrm{~min}$ ); and then cooling at $40^{\circ} \mathrm{C}$ for $30 \mathrm{sec}$. Each reaction was performed in triplicate. Relative mRNA expression levels of miR-132 were calculated using the $2^{-\Delta \Delta \mathrm{Cq}}$ method (30).

Statistical analysis. Statistical analysis was conducted using SPSS 20.0 (IBM SPSS, Armonk, NY, USA) for Windows. Independent samples t-test and one-way analysis of variance were used to determine the differences between the groups. Data were presented as the mean \pm standard deviation. Receiver operating characteristic (ROC) curve was used to identify the predictive power of miR-132. Spearman correlation analysis was performed to investigate the association between miR-132 expression levels and clinicopathological parameters. Kaplan-Meier and log-rank tests were performed to assess the association between the expression levels of miR-132 and recurrence in patients with HCC. All reported P-values were two tailed, and $\mathrm{P}<0.05$ was considered to indicate a statistically significant difference.

\section{Results}

miR-132 expression is downregulated in HCC. Following normalization against RNU6B and RNU48 expression levels, the expression levels of miR-132 in HCC tissues was demonstrated to be significantly decreased, as compared with adjacent non-tumorous tissues (1.9245 \pm 0.7564 vs. 2.7326 \pm 1.1475 ; $\mathrm{P}<0.001$; Table I). The area under curve (AUC) of ROC used to distinguish cancerous from non-cancerous tissue was 0.711 for miR-132 expression [95\% confidence interval (CI), 0.637-0.785; $\mathrm{P}<0.001$; Fig. 1] and the optimal cut-off value was 2.25 . Thus, the results indicated that miR-132 expression was downregulated in HCC.

Association of miR-132 expression with clinicopathological features in HCC patients. The associations between miR-132 expression levels and pathological characteristics were analyzed in order to better elucidate the potential role of miR-132 in the development and progression of HCC. The results suggested that the expression levels of miR-132 were significantly decreased in HCC tissues with distant metastasis 
Table I. Association between the expression of miR-132 and clinicopathological features in patients with HCC.

\begin{tabular}{|c|c|c|c|c|}
\hline \multirow[b]{2}{*}{ Clinicopathological features } & \multirow[b]{2}{*}{$\mathrm{N}$} & \multicolumn{3}{|c|}{ Relative expression of miRNA-132 (2 $\left.2^{-\Delta \Delta \mathrm{Cq}}\right)$} \\
\hline & & Mean $\pm \mathrm{SD}$ & t-value & P-value \\
\hline Tissue & & & -5.731 & $<0.001$ \\
\hline Adjacent non-cancerous liver & 95 & $2.7326 \pm 1.1475$ & & \\
\hline $\mathrm{HCC}$ & 95 & $1.9245 \pm 0.7564$ & & \\
\hline Age & & & 0.696 & 0.488 \\
\hline$\geq 50$ years & 46 & $1.9804 \pm 0.8967$ & & \\
\hline$<50$ years & 49 & $1.8720 \pm 0.6006$ & & \\
\hline Gender & & & 0.381 & 0.704 \\
\hline Male & 75 & $1.9399 \pm 0.7858$ & & \\
\hline Female & 20 & $1.8670 \pm 0.6490$ & & \\
\hline Differentiation & & & 0.272 & 0.763 \\
\hline High & 6 & $1.9167 \pm 0.9745$ & & \\
\hline Moderate & 60 & $1.8837 \pm 0.7898$ & & \\
\hline Low & 29 & $2.0107 \pm 0.6522$ & & \\
\hline Size & & & 0.007 & 0.994 \\
\hline$<5 \mathrm{~cm}$ & 8 & $1.9233 \pm 0.8599$ & & \\
\hline$\geq 5 \mathrm{~cm}$ & 77 & $1.9248 \pm 0.7363$ & & \\
\hline Tumor nodes & & & 0.370 & 0.712 \\
\hline Single & 52 & $1.9508 \pm 0.7608$ & & \\
\hline Multi & 43 & $1.8928 \pm 0.7588$ & & \\
\hline Metastasis & & & 2.193 & 0.031 \\
\hline Without metastasis & 46 & $2.0967 \pm 0.7740$ & & \\
\hline With metastasis & 49 & $1.7629 \pm 0.7096$ & & \\
\hline Clinical TNM stage & & & 2.323 & 0.022 \\
\hline I-II & 22 & $2.2455 \pm 0.7900$ & & \\
\hline III-IV & 73 & $1.8278 \pm 0.7238$ & & \\
\hline Portal vein tumor embolus & & & 0.261 & 0.794 \\
\hline- & 63 & $1.9390 \pm 0.8197$ & & \\
\hline+ & 32 & $1.8959 \pm 0.6243$ & & \\
\hline Vaso-invasion & & & -0.044 & 0.965 \\
\hline- & 59 & $1.9219 \pm 0.8013$ & & \\
\hline+ & 36 & $1.9289 \pm 0.6873$ & & \\
\hline Tumor capsular infiltration & & & 2.264 & 0.026 \\
\hline With complete capsule & 45 & $2.1058 \pm 0.7603$ & & \\
\hline No capsule or infiltration & 50 & $1.7614 \pm 0.7219$ & & \\
\hline $\mathrm{HCV}$ & & & 1.023 & 0.309 \\
\hline- & 63 & $1.9811 \pm 0.7596$ & & \\
\hline+ & 32 & $1.8131 \pm 0.7494$ & & \\
\hline $\mathrm{HBV}$ & & & 4.594 & $<0.001$ \\
\hline- & 17 & $2.6176 \pm 0.9534$ & & \\
\hline+ & 78 & $1.7735 \pm 0.6167$ & & \\
\hline AFP & & & -1.803 & 0.075 \\
\hline- & 41 & $2.0722 \pm 0.8840$ & & \\
\hline+ & 38 & $1.7634 \pm 0.5986$ & & \\
\hline Cirrhosis & & & -1.654 & 0.101 \\
\hline- & 50 & $2.0452 \pm 0.7716$ & & \\
\hline+ & 45 & $1.7904 \pm 0.7241$ & & \\
\hline NM23 & & & 2.146 & 0.034 \\
\hline- & 20 & $2.2410 \pm 0.6714$ & & \\
\hline+ & 75 & $1.8401 \pm 0.7594$ & & \\
\hline
\end{tabular}


Table I. Continued.

\begin{tabular}{|c|c|c|c|c|}
\hline \multirow[b]{2}{*}{ Clinicopathological features } & \multirow[b]{2}{*}{$\mathrm{N}$} & \multicolumn{3}{|c|}{ Relative expression of miRNA-132 (2- $\left.2^{-\Delta \mathrm{Cq}}\right)$} \\
\hline & & Mean \pm SD & t-value & P-value \\
\hline MTDH1 & & & -0.133 & 0.895 \\
\hline- & 38 & $1.9055 \pm 0.8265$ & & \\
\hline$+/++/+++$ & 51 & $1.9275 \pm 0.7251$ & & \\
\hline MTDH2 & & & 0.187 & 0.852 \\
\hline$-/+$ & 50 & $1.9316 \pm 0.7788$ & & \\
\hline$++/+++$ & 39 & $1.9008 \pm 0.7580$ & & \\
\hline P53 & & & 1.064 & 0.290 \\
\hline- & 40 & $2.0212 \pm 0.6458$ & & \\
\hline+ & 55 & $1.8542 \pm 0.8262$ & & \\
\hline $\mathrm{P} 21$ & & & 0.201 & 0.841 \\
\hline- & 62 & $1.9360 \pm 0.7050$ & & \\
\hline+ & 33 & $1.9030 \pm 0.8558$ & & \\
\hline VEGF & & & 0.431 & 0.667 \\
\hline- & 25 & $1.9808 \pm 0.7791$ & & \\
\hline+ & 70 & $1.9044 \pm 0.7528$ & & \\
\hline Ki-67 labeling index & & & 2.893 & 0.005 \\
\hline Low & 47 & $2.1430 \pm 0.7889$ & & \\
\hline High & 48 & $1.7106 \pm 0.6637$ & & \\
\hline MVD & & & 1.229 & 0.222 \\
\hline Low & 47 & $2.0206 \pm 0.7705$ & & \\
\hline High & 48 & $1.8304 \pm 0.7381$ & & \\
\hline
\end{tabular}

HCC, hepatocellular carcinoma; HCV, hepatitis C virus; HBV, hepatitis B virus; AFP, $\alpha$-fetoprotein; MTDH, metadherin; VEGF, vascular endothelial growth factor; MVD, microvessel density.

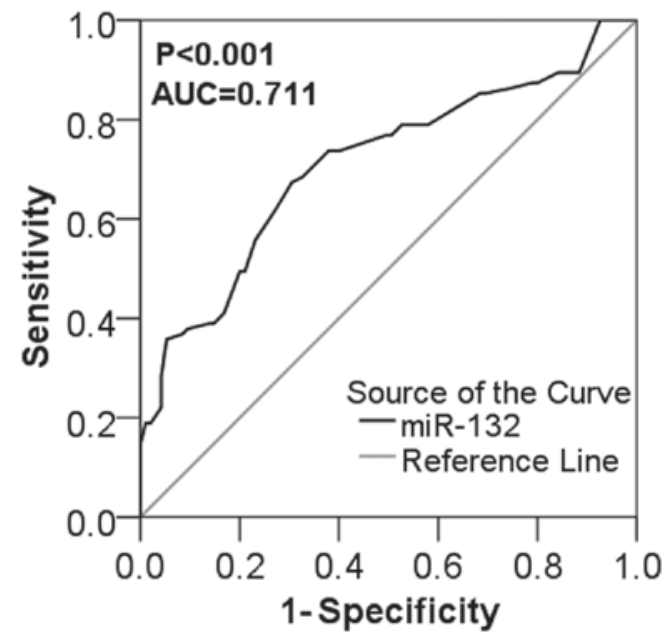

Figure 1. Receiver operating characteristic (ROC) curve of miR-132 was used to distinguish hepatocellular carcinoma. The AUC of the ROC of miR-132 for HCC was 0.711 (95\% confidence interval, 0.637-0.785; $\mathrm{P}<0.001)$. AUC, area under the curve.

$(\mathrm{P}=0.031)$, advanced clinical TNM stage $(\mathrm{P}=0.022)$ and tumor infiltration or no capsule $(\mathrm{P}=0.026)$, as compared with the adjacent non-cancerous tissues (Table I; Fig. 2). Similar outcomes were observed in the HBV-positive group $(\mathrm{P}<0.001)$,
NM23-expressed group ( $\mathrm{P}=0.034)$, and high Ki-67 labeling index (LI) group $(\mathrm{P}=0.005)$ (Table I; Fig. 2). No significant differences were detected in the expression levels of miR-132 and age, gender, histological differentiation, tumor size, tumor nodes, portal vein tumor embolus, micro-vascular invasion, hepatitis $C$ virus, $\alpha$-fetoprotein, para-carcinoma cirrhosis, metadherin, p53, p21, vascular endothelial growth factor, or microvessel density (Table I). Spearman correlation analysis was performed to investigate these associations. Positive results were detected between the expression levels of miR-132 and capsules $(r=-0.207 ; \mathrm{P}=0.044)$, HBV $(r=-0.351 ; \mathrm{P}<0.001)$, NM23 ( $r=-0.220 ; \mathrm{P}=0.032)$, and Ki-67 LI $(r=-0.264 ; \mathrm{P}=0.010)$. The cut-off value for miR-132 was 2.15. False positive and false negative rates were 0.22 and 0.556 , respectively. Therefore, the results revealed that miR-132 expression was associated with several clinical parameters in HCC.

Recurrence analysis. Median duration of follow-up was $32.78 \pm 1.43$ months (range, 2.68-68.00 months) for the patients who were successfully followed up. Among the $70 \mathrm{HCC}$ patients with recurrence data included in the present study, 59 exhibited recurrent tumors and data from 11 patients were not included due to subsequent mortality, withdrawal or loss to follow-up. The median level of miR-132 expression among the 70 patients followed up was 1.89 . Accordingly, 1.89 was used 


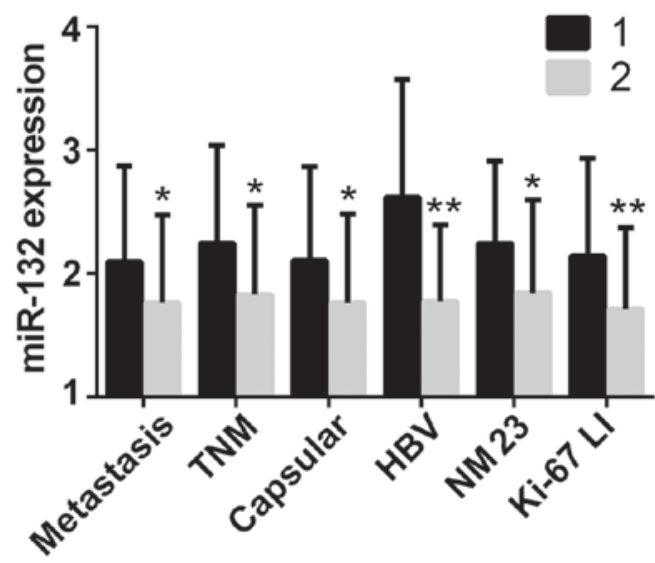

Figure 2. Statistically significant correlations between miR-132 expression levels and clinicopathological parameters. miR-132 expression levels were significantly downregulated in hepatocellular carcinoma tissues with distant metastasis $(\mathrm{P}=0.031)$, advanced clinical TNM stage $(\mathrm{P}=0.022)$ and tumor infiltration or no capsule $(\mathrm{P}=0.026)$, as well as the hepatitis $\mathrm{B}$ virus (HBV)-positive group $(\mathrm{P}<0.001)$, the NM23-expressed group $(\mathrm{P}=0.034)$, and the high Ki-67 labeling index (LI) group $(\mathrm{P}=0.005)$. ${ }^{*} \mathrm{P}<0.05$ and ${ }^{* *} \mathrm{P}<0.01$, vs. group 1. Metastasis: 1 , without metastasis; 2 , with metastasis. TNM 1, I-II; 2, III-IV. Capsular: 1, with complete capsule; 2, no capsule or infiltration. HBV: 1, HBV-negative; 2, HBV-negative. NM23: 1, NM23-negative; 2, NM23-positive. Ki-67 LI: 1, low; 2, high. TNM, tumor, node and metastatis; $\mathrm{HBV}$, hepatitis B virus; NM23

as a cut-off value to divide the 70 patients into two respective groups, low expression $(<1.89 ; n=35)$ and high expression $(>1.89 ; n=35)$. The overall recurrent period of the whole group was 57.10 months (95\% CI, 51.46-62.73). The recurrent period in the high expression group (58.68 months; $95 \%$ CI, 51.59-65.76) was longer than the low expression group (50.95 months; 95\% CI, 45.71-56.20) despite the limited statistical significance $\left(\chi^{2}=0.430 ; \mathrm{P}=0.512 \log\right.$-rank test). Thus, the results demonstrated that the high miR-132 expression group showed a longer recurrent period by $\sim 8$ months compared with the low expression group.

\section{Discussion}

The expression of miR-132 in human cancer has attracted a large amount of research. Its molecular mechanisms have been studied in osteosarcoma (31), colorectal cancer (13), pituitary tumor (32), prostate cancer (21), breast cancer (15), lung cancer $(33,34)$ and pancreatic cancer (17-19). The majority of studies have demonstrated the suppressive role of miR-132 in different classes of cancers via various novel molecule networks. For example by repressing CCNE1 expression (31), targeting zinc finger E-box-binding homeobox 2 (ZEB2) (13), Sox5 (32), hematological and neurological expressed 1 (HN1) (15) or ZEB2 (33) and being methylation-silenced and antimetastatic in PCa controlling cellular adhesion (21), as well as via the induction of acetylcholinesterase-independent apoptosis (31). All of these studies mention identified miR-132 as a tumor suppressor. However, a discrepancy in the data was detected in pancreatic cancer. Luo et al (19) demonstrated that stem-cell-like BxPC-3-LN cells expressed lower levels of miR-132 than the parental BxPC-3 cells. Zhang et al (17) further supported this finding by demonstrating the downregulation of miR-132 in pancreatic cancer via promoter methylation.
Researchers have also investigated the clinical significance of miR-132 in various tumors, where greater divergence emerged by predominantly focusing on the different expression levels of miR-132 between cancerous tissues and corresponding non-cancerous tissues. miR-132 upregulation was observed in gastric cancer $(22)$, glioma $(23,35)$ and pancreatic cancer (18). Conversely, miR-132 downregulation was detected in osteosarcoma $(31,36)$, colorectal cancer (13), ductal carcinoma in situ of the breast (16), pancreatic cancer (17) and breast cancer (15), where lower levels of miR-132 were observed in cancerous tissues, as compared with corresponding non-cancerous tissues.

The clinical application of miR-132 remains a hot topic in associated research. According to Cote et al (20), miR-132 expressed in plasma may be used as a diagnostic test for pancreatic ductal adenocarcinoma when in conjunction with other miRNAs; whereas Chung et al (37) suggested that the downregulation of miR-132 in serum may be considered as one of the novel biomarkers in serous ovarian cancer. Furthermore, Salendo et al (14) demonstrated that miR-132 may be able to identify the chemoradiosensitivity of colorectal cancer cells. As for its utilization in differential diagnosis, Lages et al (24) concluded that deregulated miR-132 may facilitate the proper discrimination of oligodendroglioma from glioblastoma.

In the present study, RT-qPCR was performed to detect the expression levels of miR-132 in 95 paired HCC and adjacent non-cancerous liver tissues to explore correlations with clinicopathological features. Only one previous study has investigated miR-132 in HCC, which predominantly focused on the role of miR-132 in the mechanism of HBV-mediated hepatocarcinogenesis (25). The present study focused on the correlations between miR-132 and clinicopathological parameters, and a larger cohort of 95 patients was investigated compared with only 20 in the previous study. Furthermore, recurrent free survival analysis was performed in the present study, which the previous research lacked.

Concerning the expression of miR-132 in HCC, the present findings were consistent with those published by Wei et al (25), as the expression of miR-132 in HCC was significantly reduced, as compared with the corresponding normal tissues $(\mathrm{P}<0.001)$. Wei et al (25) suggested that the downregulation of miR-132 may be modulated by HBx expression via DNA methylation. This hypothesis may help to explain the present results despite the difference that all their cancerous tissues were HBV-associated HCC tissues and various HCC tissues were not included. Meanwhile, the AUC of the expression level of miR-132 was 0.711 (95\% CI, 0.637-0.785; P<0.001), which implied that miR-132 may be used as a reference index in the diagnosis of HCC.

In an attempt to further complement the study conducted by Wei et al (25), the correlations between miR-132 expression levels and major clinicopathological features in HCC were explored, which was absent in their study. Firstly, decreased expression levels of miR-132 were observed in HCC tissues with distant metastasis $(\mathrm{P}=0.031)$, advanced clinical TNM stage $(\mathrm{P}=0.022)$ and tumor infiltration or no capsule $(\mathrm{P}=0.026)$. These findings inferred a tumor-suppressing role, which suggests that miR-132 may have a role in HCC progression. Secondly, the associations between miR-132 expression and other conventional biomarkers in HCC, including HBV, 
NM23 and Ki-67, were also investigated. HBV infection is a common risk factor for the development of HCC (38). Nm23 gene is a putative metastatic suppressor gene (39) and Ki-67 LI can be used to indicate cell proliferative activity (40). miR-132 expression levels were significantly reduced in the HBV-positive $(\mathrm{P}<0.001), \mathrm{NM} 23$-expressed $(\mathrm{P}=0.034)$, and high Ki-67 LI $(\mathrm{P}=0.005)$ groups. Spearman correlation analysis demonstrated positive results between the expression of miR-132 and HBV ( $r=-0.351, \mathrm{P}<0.001), \mathrm{NM} 23(r=-0.220$, $\mathrm{P}=0.032)$, and Ki-67 LI ( $r=-0.264, \mathrm{P}=0.010)$. Taken together, these results demonstrated that the expression of miR-132 was elevated in HCC cells with reduced cell proliferation, indicated that miR-132 may be associated with cell proliferation in HCC.

Recurrence analysis was also performed in the present study. Followed-up patients demonstrated a median of follow-up duration of 32.78 \pm 1.43 months (range, 2.68-68.00 months). The cohort, which was composed of 59 cases with recurrent tumors and recurrence data as well as 11 censored cases, exhibited an overall recurrent duration of 57.10 months (95\% CI, 51.46-62.73). As to the recurrent period, the high expression group $(>1.8900, \mathrm{n}=35)$ exhibited a longer duration of 58.68 months (95\% CI, 51.59-65.76), as compared with the low expression group $(<1.8900 ; n=35)$ (50.95 months; 95\% CI, 45.71-56.20) in spite of the inferior statistical value $\left(\chi^{2}=0.430 ; \mathrm{P}=0.512\right.$ log-rank test $)$.

The findings of the present study, which was the first to include recurrent analysis to investigate the correlations between miR-132 and mainstream clinicopathological characteristics in HCC, indicated that miR-132 may be significantly decreased in HCC and may perform as a tumor suppressive gene in HCC development. Nevertheless, some limitations still exist. Firstly, limited insights were emphasized in terms of the molecular mechanisms. Given the similar results of decreased miR-132 published by Wei et al (25), their theory that downregulation of miR-132 may result from the HBx expression via DNA methylation may also apply to the present study. Other targets in previous research into miR-132 in cancer, such as ZEB2 (13), Sox5 (32), HN1 (15) and ZEB2 (33), should not be ignored since consistent suppressive roles of miR-132 were observed. Furthermore, tissue analysis was employed in the present study, which has various disadvantages over non-invasive methods such as serum detection. Future studies should aim to harvest tissue and serum samples of HCC in order to investigate the molecular networks or mechanisms of miR-132 in HCC with a larger cohort.

In conclusion, the present study was the first to investigate the associations between miR-132 and clinicopathological parameters, including recurrence, in patients with HCC. The results demonstrated that miR-132 is downregulated in HCC. These findings strongly supported the hypothesis that miR-132 serves as a tumor suppressor in the development of HCC, and HCC patients with downregulated miR-132 may suffer from poorer outcomes. A subsequent study has been designed to investigate the potential underlying mechanisms between HCC and miR-132 based on the results from the present study.

\section{Acknowledgements}

The present study was supported by the Fund of Guangxi Natural Scientific Research (grant no. 2013GXNSFBA019191).

\section{References}

1. Ferlay J, Shin HR, Bray F, Forman D, Mathers C and Parkin DM: Estimates of worldwide burden of cancer in 2008: GLOBOCAN 2008. Int J Cancer 127: 2893-2917, 2010.

2. Schwartz M, Roayaie S and Konstadoulakis M: Strategies for the management of hepatocellular carcinoma. Nat Clin Pract Oncol 4: 424-432, 2007

3. El-Serag HB, Marrero JA, Rudolph L and Reddy KR: Diagnosis and treatment of hepatocellular carcinoma. Gastroenterology 134: 1752-1763, 2008

4. Blum HE: Hepatocellular carcinoma: Therapy and prevention. World J Gastroenterol 11: 7391-7400, 2005.

5. Cho WC: OncomiRs: The discovery and progress of microRNAs in cancers. Mol Cancer 6: 60, 2007.

6. Bartel DP: MicroRNAs: Genomics, biogenesis, mechanism, and function. Cell 116: 281-297, 2004.

7. Calin GA, Sevignani C, Dumitru CD, Hyslop T, Noch E, Yendamuri S, Shimizu M, Rattan S, Bullrich F, Negrini $M$ and Croce CM: Human microRNA genes are frequently located at fragile sites and genomic regions involved in cancers. Proc Natl Acad Sci USA 101: 2999-3004, 2004.

8. Kent OA and Mendell JT: A small piece in the cancer puzzle: microRNAs as tumor suppressors and oncogenes. Oncogene 25: 6188-6196, 2006.

9. Li G, Shen Q, Li C, Li D, Chen J and He M: Identification of circulating MicroRNAs as novel potential biomarkers for hepatocellular carcinoma detection: A systematic review and meta-analysis. Clin Transl Oncol 17: 684-693, 2015.

10. Zhang K, Zhang Y, Liu C, Xiong Y and Zhang J: MicroRNAs in the diagnosis and prognosis of breast cancer and their therapeutic potential (review). Int J Oncol 45: 950-958, 2014.

11. Usó M, Jantus-Lewintre E, Sirera R, Bremnes RM and Camps C: miRNA detection methods and clinical implications in lung cancer. Future Oncol 10: 2279-2292, 2014.

12. Budhu A, Jia HL, Forgues M, Liu CG, Goldstein D, Lam A, Zanetti KA, Ye QH, Qin LX, Croce CM, et al: Identification of metastasis-related microRNAs in hepatocellular carcinoma. Hepatology 47: 897-907, 2008.

13. Zheng YB, Luo HP, Shi Q, Hao ZN, Ding Y, Wang QS, Li SB, Xiao GC and Tong SL: miR-132 inhibits colorectal cancer invasion and metastasis via directly targeting ZEB2. World J Gastroenterol 20: 6515-6522, 2014.

14. Salendo J, Spitzner M, Kramer F, Zhang X, Jo P, Wolff HA, Kitz J, Kaulfuß S, Beißbarth T, Dobbelstein M, et al: Identification of a microRNA expression signature for chemoradiosensitivity of colorectal cancer cells, involving miRNAs-320a, -224, -132 and let7g. Radiother Oncol 108: 451-457, 2013.

15. Zhang ZG, Chen WX, Wu YH, Liang HF and Zhang BX: MiR-132 prohibits proliferation, invasion, migration, and metastasis in breast cancer by targeting HN1. Biochem Biophys Res Commun 454: 109-114, 2014.

16. Li S, Meng H, Zhou F, Zhai L, Zhang L, Gu F, Fan Y, Lang R, Fu L, $\mathrm{Gu} \mathrm{L}$ and Qi L: MicroRNA-132 is frequently down-regulated in ductal carcinoma in situ (DCIS) of breast and acts as a tumor suppressor by inhibiting cell proliferation. Pathol Res Pract 209: $179-183,2013$.

17. Zhang S, Hao J, Xie F, Hu X, Liu C, Tong J, Zhou J, Wu J and Shao C: Downregulation of miR-132 by promoter methylation contributes to pancreatic cancer development. Carcinogenesis 32: 1183-1189, 2011.

18. Park JK, Henry JC, Jiang J, Esau C, Gusev Y, Lerner MR, Postier RG, Brackett DJ and Schmittgen TD: miR-132 and miR-212 are increased in pancreatic cancer and target the retinoblastoma tumor suppressor. Biochem Biophys Res Commun 406: 518-523, 2011.

19. Luo G, Long J, Cui X, Xiao Z, Liu Z, Shi S, Liu L, Liu C, Xu J, $\mathrm{Li} \mathrm{M}$ and $\mathrm{Yu}$ X: Highly lymphatic metastatic pancreatic cancer cells possess stem cell-like properties. Int J Oncol 42: 979-984, 2013.

20. Cote GA, Gore AJ, McElyea SD, Heathers LE, Xu H, Sherman S and Korc M: A pilot study to develop a diagnostic test for pancreatic ductal adenocarcinoma based on differential expression of select miRNA in plasma and bile. Am J Gastroenterol 109: 1942-1952, 2014.

21. Formosa A, Lena AM, Markert EK, Cortelli S, Miano R, Mauriello A, Croce N, Vandesompele J, Mestdagh P, Finazzi-Agrò E, et al: DNA methylation silences miR-132 in prostate cancer. Oncogene 32: 127-134, 2013. 
22. Liu X, Yu H, Cai H and Wang Y: The expression and clinical significance of miR-132 in gastric cancer patients. Diagn Pathol 9: 57, 2014.

23. Liu Q, Liao F, Wu H, Cai T, Yang L, Wang ZF and Zou R: Upregulation of miR-132 expression in glioma and its clinica significance. Tumour Biol 35: 12299-12304, 2014.

24. Lages E, Guttin A, El Atifi M, Ramus C, Ipas H, Dupré I, Rolland D, Salon C, Godfraind C, deFraipont F, et al: MicroRNA and target protein patterns reveal physiopathological features of glioma subtypes. PLoS One 6: e20600, 2011.

25. Wei X, Tan C, Tang C, Ren G, Xiang T, Qiu Z, Liu R and Wu Z: Epigenetic repression of miR-132 expression by the hepatitis $\mathrm{B}$ virus $\mathrm{x}$ protein in hepatitis $\mathrm{B}$ virus-related hepatocellular carcinoma. Cell Signal 25: 1037-1043, 2013.

26. Gan TQ, Tang RX, He RQ, Dang YW, Xie Y and Chen G: Upregulated MiR-1269 in hepatocellular carcinoma and its clinical significance. Int J Clin Exp Med 8: 714-721, 2015.

27. Pan L, Huang S, He R, Rong M, Dang Y and Chen G: Decreased expression and clinical significance of miR-148a in hepatocellular carcinoma tissues. Eur J Med Res 19: 68, 2014.

28. Rong M, He R, Dang Y and Chen G: Expression and clinicopathological significance of miR-146a in hepatocellular carcinoma tissues. Ups J Med Sci 119: 19-24, 2014.

29. Rong M, Chen G and Dang Y: Increased miR-221 expression in hepatocellular carcinoma tissues and its role in enhancing cell growth and inhibiting apoptosis in vitro. BMC Cancer 13: 21,2013.

30. Livak KJ and Schmittgen TD: Analysis of relative gene expression data using real-time quantitative PCR and the 2(-Delta Delta C(T)) method. Methods 25: 402-408, 2001

31. Wang J, Xu G, Shen F and Kang Y: miR-132 targeting cyclin E1 suppresses cell proliferation in osteosarcoma cells. Tumour Biol 35: 4859-4865, 2014.

32. Renjie W and Haiqian L: MiR-132, miR-15a and miR-16 synergistically inhibit pituitary tumor cell proliferation, invasion and migration by targeting Sox 5. Cancer Lett 356: 568-578, 2015.
33. You J, Li Y, Fang N, Liu B, Zu L, Chang R, Li X and Zhou Q: MiR-132 suppresses the migration and invasion of lung cancer cells via targeting the EMT regulator ZEB2. PLoS One 9: e91827, 2014.

34. Zhang B, Lu L, Zhang X, Ye W, Wu J, Xi Q and Zhang X: Hsa-miR-132 regulates apoptosis in non-small cell lung cancer independent of acetylcholinesterase. J Mol Neurosci 53: 335-344, 2014.

35. Parker NR, Correia N, Crossley B, Buckland ME, Howell VM and Wheeler HR: Correlation of MicroRNA 132 Up-regulation with an unfavorable clinical outcome in patients with primary glioblastoma multiforme treated with radiotherapy plus concomitant and adjuvant temozolomide chemotherapy. Transl Oncol 6: 742-748, 2013.

36. Yang J, Gao T, Tang J, Cai H, Lin L and Fu S: Loss of microRNA-132 predicts poor prognosis in patients with primary osteosarcoma. Mol Cell Biochem 381: 9-15, 2013.

37. Chung YW, Bae HS, Song JY, Lee JK, Lee NW, Kim T and Lee KW: Detection of microRNA as novel biomarkers of epithelial ovarian cancer from the serum of ovarian cancer patients. Int J Gynecol Cancer 23: 673-679, 2013.

38. Kumar M, Kumar R, Hissar SS, Saraswat MK, Sharma BC, Sakhuja P and Sarin SK: Risk factors analysis for hepatocellular carcinoma in patients with and without cirrhosis: A case-control study of 213 hepatocellular carcinoma patients from India. J Gastroenterol Hepatol 22: 1104-1111, 2007.

39. Takada S and Koike K: Trans-activation function of a 3 'truncated $\mathrm{X}$ gene-cell fusion product from integrated hepatitis B virus DNA in chronic hepatitis tissues. Proc Natl Acad Sci USA 87: 5628-5632, 1990.

40. Koskinas J, Petraki K, Kavantzas N, Rapti I, Kountouras D and Hadziyannis S: Hepatic expression of the proliferative marker $\mathrm{Ki}-67$ and 553 protein in HBV or HCV cirrhosis in relation to dysplastic liver cell changes and hepatocellular carcinoma. J Viral Hepat 12: 635-641, 2005. 